\title{
Comparison of four different pain relief methods during hysterosalpingography: A randomized controlled study
}

\author{
Bekir Serdar Unlu MD ${ }^{1}$, Mehmet Yilmazer $M D^{1}$, Gulengul Koken $M D^{1}$, Dagistan Tolga Arioz $M D^{1}$, \\ Ebru Unlu MD², Elif Dogan Baki MD², Cemile Kurttay MD¹, Osman Karacin MD ${ }^{1}$
}

\begin{abstract}
BS Unlu, M Yilmazer, G Koken, et al. Comparison of four different pain relief methods during hysterosalpingography: A randomized controlled study. Pain Res Manag 2015;20(2):107-111.
\end{abstract}

BACKGROUND: Hysterosalpingography (HSG) is the most commonly used method for evaluating the anatomy and patency of the uterine cavity and fallopian tubes, and is an important tool in the evaluation of infertility. The most frequent side effect is the pain associated with the procedure.

OBJECTIVES: To evaluate four analgesic methods to determine the most useful method for reducing discomfort associated with HSG.

METHODS: In the present prospective study, 75 patients undergoing HSG for evaluation of infertility were randomly assigned to four groups: $550 \mathrm{mg}$ of a nonsteroidal anti-inflammatory drug (NSAID) (group 1); $550 \mathrm{mg}$ NSAID + paracervical block (group 2); $550 \mathrm{mg}$ NSAID + paracervical analgesic cream (group 3); or $550 \mathrm{mg}$ NSAID + intrauterine analgesic instillation (group 4). A visual analogue scale was used to assess the pain perception at five predefined steps.

RESULTS: Instillation of the liquids used for HSG was found to be the most painful step of HSG, and this step was where the only significant difference among groups was observed. When comparing visual analogue scale scores, group 2 and group 3 reported significantly less pain than the other groups. Group 1 reported significantly higher mean $( \pm S D)$ scores $(7.2 \pm 1.6)$ compared with groups 2 and $3(4.7 \pm 2.5$ and $3.8 \pm 2.4$, respectively) $(\mathrm{P}<0.001)$. In addition, group 2 reported significantly less pain than group 4 ( $4.7 \pm 2.5$ versus $6.7 \pm 1.8$, respectively) $(\mathrm{P}<0.02)$.

CONCLUSIONS: For effective pain relief during HSG, in addition to $550 \mathrm{mg}$ NSAID, local application of lidocaine cream to the posterior fornix of the cervix uteri and paracervical lidocaine injection into the cervix uteri appear to be the most effective methods.

Key Words: Hysterosalphingography; Intrauterine lidocaine; Lidocaine cream; Pain relief; Paracervical block; Visual analogue scale

In developed countries, the prevalence of infertility is approximately $12 \%(6.6 \%$ to $26.4 \%)$ among those of reproductive age (1). Infertility is clinically defined as the failure to achieve a pregnancy after $\geq 12$ months of regular unprotected sexual intercourse (2). The factors that affect female fertility include pathologies involving the uterus, cervix, ovaries, fallopian tubes, endometrium and peritoneum. Fallopian tube abnormalities account for $30 \%$ to $40 \%$ of all female infertility cases (3).

Hysterosalpingography (HSG) is the fluoroscopic evaluation of the female genital tract after injection of a radio-opaque medium through the cervical canal (1). It is commonly used to determine the causes of infertility and frequent miscarriages by examining the internal luminal morphology of the endocervical canal, uterine cavity and fallopian tubes, and associated abnormalities such as congenital anomalies, neoplasia and inflammatory changes $(4,5)$. The number of HSGs performed per year has gradually increased with the increasing rate of
La comparaison entre quatre méthodes pour soulager de la douleur d'une hystérosalpingographie : une étude aléatoire et contrôlée

HISTORIQUE : L'hystérosalpingographie (HSG), la méthode la plus utilisée pour évaluer l'anatomie et la perméabilité de la cavité utérine et des trompes de Fallope, est un outil important pour évaluer l'infertilité. La douleur associée à l'intervention en est le principal effet secondaire.

OBJECTIFS : Évaluer quatre méthodes analgésiques afin de déterminer la plus utile pour limiter les malaises associés à l'HSG.

MÉTHODOLOGIE : Dans la présente étude prospective, 75 patientes qui avaient subi une HSG pour évaluer leur infertilité ont été réparties au hasard entre quatre groupes : $550 \mathrm{mg}$ d'anti-inflammatoires non stéroïdiens (AINS) (groupe 1), $550 \mathrm{mg}$ d'AINS + bloc paracervical (groupe 2), $550 \mathrm{mg}$ d'AINS + crème analgésique paracervicale (groupe 3) ou $550 \mathrm{mg}$ d'AINS + instillation intra-utérine d'analgésique (groupe 4). Une échelle visuelle analogue était utilisée pour évaluer la perception de la douleur à cinq étapes prédéfinies.

RÉSULTATS : L'instillation de liquides utilisée pour l'HSG était l'étape la plus douloureuse de l'intervention et celle qui constituait la seule différence significative entre les groupes. Lorsqu'on comparait les scores des échelles visuelles analogues, les groupes 2 et 3 déclaraient considérablement moins de douleur que les autres groupes. Le groupe 1 déclarait des scores beaucoup plus élevés $(7,2 \pm 1,6)$ que les groupes 2 et $3(4,7 \pm 2,5$ et $3,8 \pm 2,4$, respectivement $)(P<0,001)$. En outre, le groupe 2 déclarait beaucoup moins de douleur que le groupe $4(4,7 \pm 2,5$ par rapport à $6,7 \pm 1,8$, respectivement $)(\mathrm{P}<0,02)$.

CONCLUSIONS : Pour obtenir un soulagement efficace de la douleur pendant l'HSG, en plus de $550 \mathrm{mg}$ d'AINS, l'application locale de crème de lidocaïne au cul-de-sac postérieur du col de l'utérus et l'injection de lidocaïne paracervicale dans le col de l'utérus semblent représenter la méthode la plus efficace pour soulager la douleur.

infertility (eg, approximately $7.2 \%$ of the reproductive-age population in developed countries) (5).

HSG is performed during the proliferative phase, after cessation of menstruation and before ovulation, between days 7 and 11, to avoid any early pregnancies (6). This diagnostic test was originally performed with oil-soluble contrast media, but now most clinicians use water-soluble media for its cost and imaging advantages.

Pain is the most frequent side effect of HSG. Although the pain perception gradually decreases after the intervention and typically ends in $30 \mathrm{~min}$, up to $72 \%$ to $80 \%$ of patients report mild to moderate pain during the procedure $(7,8)$. Nevertheless, most women (59\%) describe this diagnostic procedure as very stressful (9). The majority of women regard a hysterosalpingogram as acutely painful because it involves placement of a cervical tenaculum, traction on the cervix, instillation of dye through a cervical cannula and tubal spilling (10).

${ }^{1}$ Department of Obstetrics and Gynecology; ${ }^{2}$ Department of Radiology; ${ }^{3}$ Department of Anesthesiology, Faculty of Medicine, Afyon Kocatepe University, Afyonkarahisar, Turkey

Correspondence: Dr Bekir Serdar Unlu, Department of Obstetrics and Gynecology, Faculty of Medicine, Kocatepe University, Dortyol Mahallesi, 2081 Sokak, No.1/15, 03040, Afyonkarahisar, Turkey. Telephone 90-5325894111, e-mail drserdarunlu@yahoo.com

OPEN ACCESS

This open-access article is distributed under the terms of the Creative Commons Attribution Non-Commercial License (CC BY-NC) (http:// creativecommons.org/licenses/by-nc/4.0/), which permits reuse, distribution and reproduction of the article, provided that the original work is properly cited and the reuse is restricted to noncommercial purposes. For commercial reuse, contact support@pulsus.com 
Water-soluble contrast appears to cause more pain because it distends the fallopian tubes and uterus more rapidly than the highviscosity oil-soluble media $(5,11)$. Another hypothesis is that pain is felt secondary to release of local prostaglandins, which result in uterine cramps. The pain is conducted by the pelvic splanchnic nerves from the cervix and lower part of the uterus, whereas pain from the fundus and the body of the uterus is conducted by hypogastric nerves (12). The prevalence of pain also differs according to the injection device used and the examiner's technique (13).

In routine practice, four analgesic procedures are used to prevent pain perception during HSG. These are: use of oral nonsteroidal antiinflammatory drugs (NSAIDs) for systemic pain medication; paracervical block for the cervical pain mechanism; application of topical analgesic cream to the uterine cervix; and intrauterine analgesic instillation for the uterine-tubal pain mechanism. Many studies have been performed in various countries regarding pain relief during HSG, and these procedures have been shown to decrease pain to some degree during HSG and sonohysterography $(10,14-16)$. However, all of these studies have highlighted the effectiveness of different analgesic techiques in comparison with placebo-control groups. To the best of our knowledge, there has been no study that has directly compared these four analgesic techniques. Also, the most painful phase in the procedure was not determined in the previous studies $(10,17,18)$.

The present study was performed to compare the effects of different analgesic methods during HSG to identify an effective analgesic modality for pain relief. In the current study, we aimed to investigate, in addition to an NSAID, which of three analgesic methods would be most effective in reducing discomfort associated with HSG in a prospective, randomized, controlled study. We also aimed to investigate the most painful phase in the HSG procedure and, therefore, to inform the patient about this step for psychological preparation and management of any anxiety.

\section{METHODS}

The present prospective, randomized study was performed between May and August 2013 at the Department of Obstetrics and Gynecology, Kocatepe University, Afyonkarahisar, Turkey. Ethics approval was obtained from the Institutional Review Board. Experimental procedures followed the ethical standards for experimentation on humans established by the Declaration of Helsinki of 1975, revised in 1983.

\section{Participants}

All patients admitted to the authors' infertility clinic were evaluated for appropriateness of participation in the study, and those who met the enrollment criteria were invited to participate. Informed consent was obtained from subjects who underwent HSG during infertility assessment. A total of 80 women were recruited for the present study using a convenience sampling method. Subsequently, a total of five patients declined to participate in the study without providing a reason. These five women were excluded, and the remaining 75 patients were randomly divided into four groups.

The groups received naproxen sodium (group 1), naproxen sodium + paracervical block ( $1 \%$ lidocaine) (group 2$)$, naproxen sodium + paracervical analgesic cream (5\% lidocaine) (group 3 ), or naproxen sodium + intrauterine analgesic instillation (1\% lidocaine) (group 4).

Subjects were given prophylactic antibiotics before the procedure. The 75 women in all four groups were instructed to self-administer a single oral dose of $550 \mathrm{mg}$ of naproxen sodium $1 \mathrm{~h}$ before the scheduled time of the procedure. Subsequently, women in group 1 received no additional medication for pain relief.

In group 2, $6 \mathrm{~mL}$ of $1 \%$ lidocaine $(2 \mathrm{mg} / \mathrm{kg}$ to $4 \mathrm{mg} / \mathrm{kg}$ ), a local anesthetic drug, was injected into the cervix in divided doses of $1.5 \mathrm{~mL}$ circumferentially at 12, 4, 6 and 8 o'clock positions; 5 min was allowed to elapse before proceeding with the HSG.

In group 3, the posterior vaginal fornix was filled with $3 \mathrm{~mL}$ of $5 \%$ lidocaine cream (Anestol Pomad, Sandoz Pharmaceuticals, Germany).
The cream was applied by a doctor to the fornix using a vaginal speculum $30 \mathrm{~min}$ before the procedure.

In group 4, women received an intrauterine instillation of $5 \mathrm{~mL}$ of $1 \%$ lidocaine $2 \mathrm{~min}$ before the procedure.

\section{Exclusion criteria}

Patients who had known stenotic cervical os; acute cervicitis; intense anxiety; a history of any allergy to local anesthetics, radio-opaque dye or anti-inflammatory medications; any recent history of acute pelvic inflammatory disease; any vaginal discharge (known to exacerbate and flare up following HSG); any other cause of chronic pelvic pain; a positive $\beta$-human chorionic gonadotropin test; or were $<18$ years of age were excluded. All participants were 18 to 40 years of age and married.

\section{Procedure}

The HSG was performed in the same room, on the same table and with the same technique by only two gynecologists to maintain consistency and limit confounding variables.

The HSG procedure was performed while the women were in a dorsal lithotomy position. A sterile metal speculum was used to visualize the uterine cervix. Antiseptic 1\% chlorhexidine solution was used to wash the vagina and cervix. For groups 1 and 3 immediately and groups 2 and 4 (intracervical block with lidocaine and intrauterine instillation of lidocaine, respectively) $5 \mathrm{~min}$ and $2 \mathrm{~min}$, respectively, before the procedure, a single-toothed tenaculum was placed on the anterior lip of the cervix transversely. A metal cannula was gently inserted into the external cervical os, the cannula and tenaculum were secured together, and the speculum was removed. Traction was placed on the tenaculum, and 15 $\mathrm{mL}$ to $20 \mathrm{~mL}$ of water-soluble iodinated contrast media (a compound of iohexol [Omnipaque $350 \mathrm{mg} / 50 \mathrm{~mL}$, Opakim, Turkey]), was instilled slowly via the cannula to prevent pain while the necessary images were obtained. After the procedure, the instruments were removed and the patient was observed for $15 \mathrm{~min}$ to $30 \mathrm{~min}$ in the clinic.

\section{Measures}

In all groups, the pain during the procedure was scored at five consecutive steps: step 1, before beginning the procedure (for baseline pain perception); step 2, just after speculum insertion; step 3, at the time of placement of the tenaculum; step 4, just after instillation of the liquids used for HSG; and step 5, 15 min after the HSG was completed and instruments removed.

At each stage of the procedure, patients were asked to rate their pain during HSG using a $0 \mathrm{~cm}$ to $10 \mathrm{~cm}$ visual analogue scale (VAS, $0=$ no pain, $10=$ worst possible pain $)(10,19)$. VAS scores were measured and recorded in real time by the same radiology technician.

Procedure time was calculated as the time between the placement of the tenaculum and the end of the procedure after the tenaculum and cannula were removed by the same radiology technician.

\section{Statistical analysis}

Original research articles in the literature were analyzed before the sample size was calculated, but none of the articles compared the three topical anesthetics among groups. The study by Bachman et al (20) was used for the calculations, with a difference of at least 1.3 on a VAS with a highest SD of 1.2 being regarded as clinically significant $(\alpha=0.05$, power $=0.80)$, and a sample size of at least 14 in each group. A one-way ANOVA test was used for analysis. If variances were determined to be homogeneous, the Tukey honest significant difference test was used; if variances were nonhomogeneous, the Tamhane test was used. Proportions were assessed using cross-tabulation, and the $\chi^{2}$ test was used to compare these proportions in different groups. Values are presented as mean $\pm \mathrm{SD}$, and for categorical variables as $\mathrm{n}(\%)$. If $\mathrm{P}<0.05$, the difference was considered to be statistically significant.

\section{RESULTS}

A total of 75 patients were included in the present study, and were randomly assigned to four groups (Figure 1). Group 1 received $550 \mathrm{mg}$ naproxen sodium $(n=20)$, group 2 received $550 \mathrm{mg}$ naproxen sodium + 
paracervical block ( $6 \mathrm{~mL} 1 \%$ lidocaine) $(\mathrm{n}=19)$, group 3 received $550 \mathrm{mg}$ naproxen sodium + paracervical analgesic cream ( $3 \mathrm{~mL} 5 \%$ lidocaine) $(\mathrm{n}=18)$, and group 4 received $550 \mathrm{mg}$ naproxen sodium + intrauterine analgesic instillation ( $5 \mathrm{~mL} 1 \%$ lidocaine) $(\mathrm{n}=18)$. No complications were observed during the procedures.

Patient age, weight, height, obstetric history, education and procedure time were not significantly different among groups (Table 1). There was no correlation between education level and pain perception $(\mathrm{P}>0.05)$. The preprocedure VAS scores of all four groups were not significantly different $(\mathrm{P}>0.05)$.

There were no differences in terms of pain scores among groups ( $P>0.05$ ) before beginning the procedure (step 1, as the point of baseline pain perception) $(0.17 \pm 0.3,0.05 \pm 0.1,0.16 \pm 0.3,0.02 \pm 0.04$, groups 1 to 4 , respectively), just after speculum insertion (step 2) $(1.3 \pm 1.1,1.3 \pm 0.62,1.2 \pm 0.8,0.4 \pm 0.8$, groups 1 to 4 , respectively), at the time of placement of the tenaculum (step 3) $(3.9 \pm 1.4,3 \pm 2.1$, $2.8 \pm 1.6,2.7 \pm 1.5$, groups 1 to 4 , respectively) and $15 \mathrm{~min}$ after the HSG was completed and instruments removed (step 5) (0.8 \pm 1.8 , $0.2 \pm 0.3,0.3 \pm 0.7,0.3 \pm 0.5$, groups 1 to 4 , respectively) (Table 2).

Instillation of the liquids used for HSG was found to be the most painful step of HSG; this step is where the only significant difference among groups was found $(\mathrm{P}<0.001)$ (Table 2). Pain perception in step 4 was significantly higher in group 1 compared with group 2 (7.2 \pm 1.6 versus $4.7 \pm 2.5$, respectively; $\mathrm{P}<0.001)$. There was also a significant difference between group 1 and group 3 ( $7.2 \pm 1.6$ versus $3.8 \pm 2.4$, respectively; $\mathrm{P}<0.001)$. In step 4 , a difference was found between group 2 and group 4, which was not as high as for the previous groups; nevertheless, this was also statistically significant $(4.7 \pm 2.5$ versus $6.7 \pm 1.8$, respectively; $\mathrm{P}<0.02)$. No differences were observed between groups 2 and 3 (4.7 \pm 2.5 and $3.8 \pm 2.4$, respectively; $\mathrm{P}=0.4$ ).

\section{DISCUSSION}

The most important finding of the present study was that local application of lidocaine cream to the posterior fornix of the cervix uteri and lidocaine injection into the cervix uteri at four different points during HSG effectively reduced pain during the procedure. However, this pain reduction effect was limited to immediately after instillation of the liquids used for visualization of the uterine cavity and fallopian tubes (step 4). Other steps of the procedures were similar in terms of pain perception according to VAS for all methods. Also, we found that step 4 was the most painful phase in the procedure; this step is where a significant difference among groups was found.

HSG is typically performed as part of an infertility work-up or in the evaluation of recurrent early pregnancy loss, and rarely to confirm tubal patency after reversal of tubal ligation or to confirm tubal occlusion after surgical sterilization. The most frequent side effect of HSG is pain. Fortunately, it is short-lived, but up to $72 \%$ to $80 \%$ of patients report mild to moderate pain during the procedure $(7,8)$. Because of this side effect, many different methods have been used to prevent pain perception during HSG. These include oral, intrauterine and

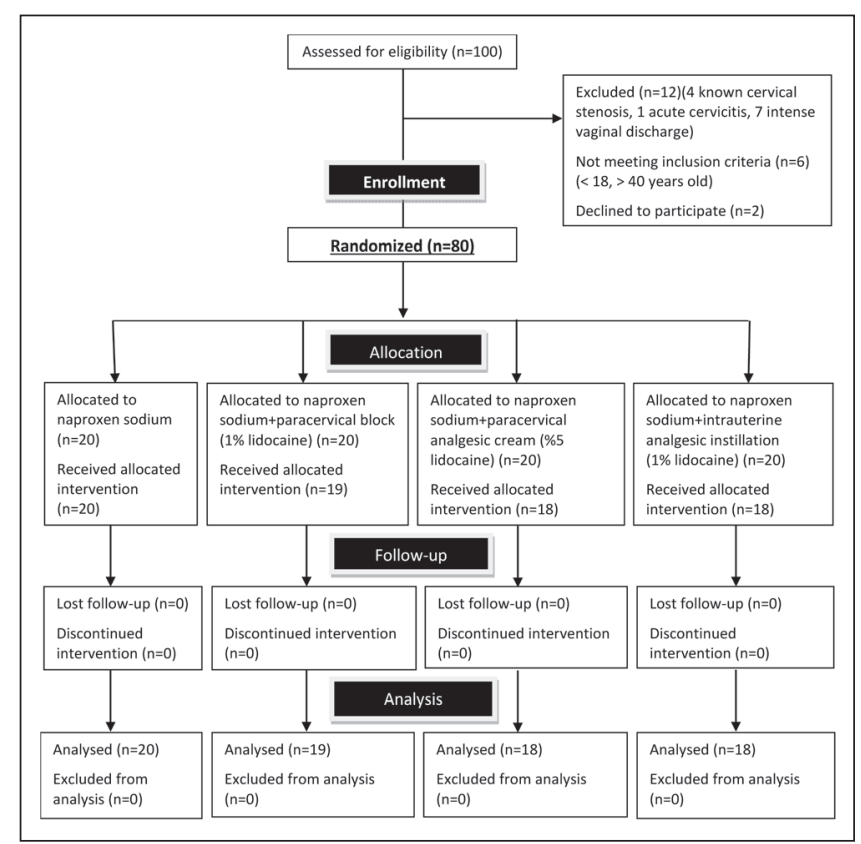

Figure 1) CONSORT flow chart

topical analgesics $(10,14,15,17-23)$. To the best of our knowledge, our study is unique in being the first study comparing different methods to prevent pain perception during HSG.

According to Duffy et al (24), in a national survey study from the United Kingdom, nonopioid analgesia (acetaminophen, acetylsalicylic acid and fenoprofen) was the most preferred prophylactic analgesic method, being offered by $52 \%$ of clinicians to patients for the prevention of pain during the HSG procedure. A Cochrane review reported that at both up to $29 \mathrm{~min}$ after the procedure and $>30 \mathrm{~min}$ after the procedure, the beneficial effects of using a nonopioid analgesic over a placebo could not be demonstrated (25). In our study, we found that group 1 had the highest VAS pain score in all steps in the HSG procedure; this finding was consistent with these studies.

According to some authors, intracervical block is believed to be the most effective method. The use of this technique for pain relief in the HSG procedure was first studied by Robinson et al (10) in 2007. According to their results, patients can tolerate pain during tenaculum placement and tenaculum traction during a HSG with intracervical block better than placebo, but this pain-relieving effect was not present for pain perception during the most painful component of the HSG, which was the instillation of contrast into the uterus. Thus, the authors concluded that intracervical block should be offered to all patients undergoing HSG with NSAIDs. A second study investigating intracervical block effectiveness in HSG procedures was performed

TABLE 1

\section{Patient characteristics}

\begin{tabular}{|c|c|c|c|c|c|}
\hline & Group $1(n=20)$ & Group $2(n=19)$ & Group $3(n=18)$ & Group $4(n=18)$ & $\mathbf{P}$ \\
\hline Age, years & $27.2 \pm 7.05$ & $27.63 \pm 4.87$ & $29.17 \pm 6.25$ & $28.28 \pm 5.82$ & NS \\
\hline Height, cm & $158.5 \pm 4.52$ & $160.05 \pm 6.08$ & $157.22 \pm 6.67$ & $160.72 \pm 4.10$ & NS \\
\hline Nulliparous, n (\%) & $17(85)$ & $14(73.7)$ & $11(61.1)$ & $13(72.2)$ & \\
\hline \multicolumn{6}{|l|}{ Education } \\
\hline$>8$ years & $5(25)$ & $5(26.3)$ & $5(27.8)$ & $6(33.3)$ & NS \\
\hline Operation time, s & $58.1 \pm 8.01$ & $54.47 \pm 6.06$ & $50.61 \pm 6.43$ & $55.61 \pm 6.96$ & NS \\
\hline
\end{tabular}

Data presented as mean $\pm S D$ unless otherwise indicated. One-way ANOVA test was used; differences were considered to be statistically significant at $P<0.05$. Group 1: 550 mg naproxen sodium; group 2: 550 mg naproxen sodium + paracervical block; group 3: 550 mg naproxen sodium + paracervical analgesic cream; group 4: $550 \mathrm{mg}$ naproxen sodium + intrauterine analgesic instillation. NS Not significant 
TABLE 2

Visual analogue scale scores in four different groups

\begin{tabular}{lccccc}
\hline Step & Group 1 & Group 2 & Group 3 & Group 4 & P \\
\hline 1 & $0.17 \pm 0.3$ & $0.05 \pm 0.1$ & $0.16 \pm 0.3$ & $0.02 \pm 0.04$ & $>0.05$ \\
2 & $1.3 \pm 1.1$ & $1.3 \pm 0.62$ & $1.2 \pm 0.8$ & $0.4 \pm 0.8$ & $>0.05$ \\
3 & $3.9 \pm 1.4$ & $3.0 \pm 2.1$ & $2.8 \pm 1.6$ & $2.7 \pm 1.5$ & $>0.05$ \\
4 & $7.2 \pm 1.6$ & $4.7 \pm 2.5$ & $3.8 \pm 2.4$ & $6.7 \pm 1.8$ & $<0.001^{\star *+1 \S \pi}$ \\
5 & $0.8 \pm 1.8$ & $0.2 \pm 0.3$ & $0.3 \pm 0.7$ & $0.3 \pm 0.5$ & $>0.05$ \\
\hline
\end{tabular}

Data presented as mean $\pm S D$ unless otherwise indicated. One-way ANOVA test was used; differences were considered to be statistically significant at $P<0.05$. Step 1: Before beginning the procedure (as point of base-line pain perception); step 2: Just after speculum insertion; step 3: At the time of placement of tenaculum; step 4: Just after instillation of the liquids used for hysterosalpingography; step 5: 15 min after the HSG completed and instruments removed. Group 1: 550 mg naproxen sodium; group 2: $550 \mathrm{mg}$ naproxen sodium + paracervical block; group 3: $550 \mathrm{mg}$ naproxen sodium + paracervical analgesic cream; group 4: $550 \mathrm{mg}$ naproxen sodium + intrauterine analgesic instillation. ${ }^{*} P<0.001$ for group 1 versus group $2 ;{ }^{\dagger} P<0.001$ for group 1 versus group $3 ; \neq P=0.4$ for group 2 versus group $3 ;$; $P=0.02$ for group 2 versus group 4 ; $\rrbracket_{P}<0.001$ for group 3 versus group 4

recently (22). In this study, the main difference from the Robinson et al (10) study was that the analgesic effect was observed at all stages of the process, even during instillation of dye and 1 min after completion of the process and removal of the instruments. Chauhan et al (22) explained this difference as due to premedication drugs. In contrast to the Robinson et al (10) study, Chauhan et al (22) used intramuscular atropin and promethazine hydrochloride $30 \mathrm{~min}$ before the procedure as premedication, which was not given in the study performed by Robinson et al, in which $800 \mathrm{mg}$ ibuprofen was given orally $30 \mathrm{~min}$ before the procedure. Interestingly, our study showed that intracervical pain block (group 2) was effective during instillation of dye compared with during placement of the tenaculum (better than the control but not significant). Although we used a similar premedication as in the Robinson et al study, our results showed no similarities to their findings. Contradictions between previous studies and our study are clearly apparent. In addition, a meta-analysis by Tangsiriwatthana et al (26) concluded that there is no definitive evidence that paracervical block is better or worse than alternative analgesic techniques in terms of efficacy for women undergoing uterine interventions.

The other technique investigated for pain relief during the HSG procedure was local application of lidocaine cream to the posterior fornix of the cervix uteri plus oral NSAID. In all groups in our study, the best results for VAS scores in step 4 were obtained in this study group. According to Liberty et al $(17,18)$, insertion of cervical instruments was the most painful step during the HSG procedure. There have been only two previous randomized controlled studies comparing local anesthetic application to cervix uteri with placebo during HSG $(17,21)$. Lorino et al (21) conducted a study in which $20 \%$ benzocaine gel was applied to the uterine cervix in one group of women, who were then compared with a group who received a placebo. The authors found a significant reduction in pain during HSG with topical benzocaine gel. In another study, it was demonstrated that topical application of $5 \%$ lidocaine-prilocaine cream to the uterine cervix before HSG significantly reduced the pain associated with this procedure (17). Based on this work, we suggest that if the pain score is unchanged between speculum insertion and contrast media instillation via catheter (except after application of the tenaculum and the cannula on the uterine cervix), then the administered pain relief method is successful. In the literature, most studies observed pain to vary during different steps of the treatment process. Pain perception was not perceived as being the same during speculum insertion compared with uterine filling or tubal spilling $(10,19,22)$. In our study, VAS scores between steps were different in group 3 (naproxen sodium + paracervical analgesic cream [5\% lidocaine]). Unlike the findings of Liberty et al (17), our pain scores were consistent with the literature $(10,17,22)$.

The final group in our study (group 4) received an intrauterine instillation of lidocaine in addition to an oral NSAID (a single oral dose of $550 \mathrm{mg}$ of naproxen sodium $1 \mathrm{~h}$ before HSG); this group had better pain relief than group 1 (only prophylactic oral NSAID) in all stages of the procedure, but this difference was not statistically significant.
Unfortunately, group 4 did not show a favourable result for pain relief compared with lidocaine injection into the cervix uteri plus oral NSAID (group 2) and local application of lidocaine cream to the cervix uteri plus oral NSAID (group 3). Several studies have analyzed the use of topical anesthetics injected into the uterine cavity to decrease the pain associated with outpatient gynecological procedures such as endometrial biopsy or office hysteroscopy $(27,28)$. In contrast, in many studies, the intrauterine use of lidocaine during painful gynecological procedures, including firsttrimester abortion, endometrial biopsy and HSG, has not been shown to be favourable for decreasing pain (19,23). According to Gupta et al (23), oral NSAID (a single oral dose of $375 \mathrm{mg}$ of naproxen $1 \mathrm{~h}$ before HSG) provides more effective pain relief than intrauterine lidocaine instillation. Frishman et al (19) showed that intrauterine lidocaine instillation had no effect on pain perception compared with placebo in the HSG procedure.

According to our study results, the most painful step in the HSG procedure was instillation of the contrast media into the uterine cavity and tubal spilling. This finding is consistent with the findings of Robinson et al (10), who suggested that the most painful component of the HSG was instillation of contrast into the uterus. However, according to Liberty et al (17), cervical instrument insertion was the most painful step in the HSG procedure. We suggest that awareness of the most painful phase during the HSG procedure is especially important for psychological preparation of the patient before this step so that anxiety can be managed.

Compared with group 1 at step 4 (oral NSAID $550 \mathrm{mg}$ ), pain reductions were $34.7 \%$ for group $2,47.3 \%$ for group 3 and $7 \%$ for group 4 . With both acute and chronic pain, the most favoured outcome is that which provides approximately $50 \%$ pain relief (29). According to this literature standard, only group 3 in our study reached effective levels of pain relief during the HSG procedure. However, in a study investigating pain relief in HSG by Costello et al (15), a reduction of $15 \%$ was considered to be clinically significant. Another study demonstrated a reduction of $>30 \%$ to be an effective level (17). Compared with these percentages, groups 2 and 3 reached an effective pain relief level in our study.

One of the limitations to our study was the use of a convenience sampling technique. We preferred this sampling technique because it is fast, inexpensive, easy to use and the subjects are readily available. However, the most obvious criticism about convenience sampling is sampling bias and that the sample is not representative of the entire population. Another limitation was that our study would have been stronger if patients were blinded to the intervention used for each group recruited into the study.

Based on our results and a review of the literature, local application of lidocaine cream to the posterior fornix of the cervix uteri and paracervical lidocaine injection into the cervix uteri appear to be the most effective pain relief methods. Pain relief with intrauterine instillation of lidocaine was found to be less effective than other pain relief methods in our study. However, intrauterine instillation of lidocaine plus oral NSAID led to a better result than oral NSAID alone. In addition, instillation of the liquids used for visualization of 
the uterine cavity and fallopian tubes (step 4) was the most painful step in the procedure.

ACKNOWLEDGEMENTS: The authors thank Dr Yunus Yildiz for statistical analysis in the study and Dilay Karademir for her assistance in the endometrial sampling procedure.

\section{REFERENCES}

1. Boivin J, Bunting L, Collins JA, Nygren KG. International estimates of infertility prevalence and treatment-seeking: Potential need and demand for infertility medical care. Hum Reprod 2007;22:1506-12.

2. Zegers-Hochschild F, Adamson GD, de Mouzon J, et al. International Committee for Monitoring Assisted Reproductive Technology (ICMART) and the World Health Organization (WHO) revised glossary of ART terminology, 2009. Fertil Steril 2009;92:1520-4.

3. Steinkeler JA, Woodfield CA, Lazarus E, Hillstrom MM. Female infertility: A systematic approach to radiologic imaging and diagnosis. Radiographics 2009;29:1353-70.

4. Fettinger S, Fanelli L. Hysterosalpingography and sonohysterography. In: Pfenninger JL, Fowler GC, eds. Pfenninger and Fowler's Procedures for Primary Care. Philadelphia: Mosby, 2011:977-83.

5. Assisted Reproductive Technology Success Rates. US Department of Health and Human Services and the Center for Disease Control and Prevention. <www.cdc.gov/ART/> (Accessed May 20, 2009).

6. Chalazonitis A, Tzovara I, Laspas F, Porfyridis P, Ptohis N, Tsimitselis G. Hysterosalpingography: Technique and applications. Curr Probl Diagn Radiol 2009;38:199-205

7. Ayida G, Kennedy S, Barlow D, Chamberlain P. A comparison of patient tolerance of hysterosalpingography-contrast sonography (HyCoSy) with Echovist-200 and X-ray hysterosalpingography for outpatient investigation of infertile women. Ultrasound Obstet Gynecol 1996;7:201-4.

8. Sanfilippo JS, Yussman MA, Smith O. Hysterosalpingography in the evaluation of infertility: A six year review. Fertil Steril 1978;30:636-43.

9. Eimers JM, Omtzigt AM, Vogelzang ET, van Ommen R, Habbema JD, te Velde ER. Physical complaints and emotional stress related to routine diagnostic procedures of the fertility investigation. J Psychosom Obstet Gynaecol 1997;18:31-5.

10. Robinson RD, Casablanca Y, Pagano KE, Arthur NA, Bates GW, Propst AM. Intracervical block and pain perception during the performance of a hysterosalpingogram: A randomized controlled trial. Obstet Gynecol 2007;109:89-93

11. Johnson NP, Farquhar CM, Hadden WE, Suckling J, Yu Y, Sadler L. The FLUSH trial - flushing with lipiodol for unexplained (and endometriosis-related) subfertility by hysterosalpingography: A randomized trial. Hum Reprod 2004;19:2043-51.

12. Moore DE. Pain associated hysterosalpingography: Ethiodol versus Salpinx media. Fertil Steril 1982;38:629-31.

13. Brubaker LM, Clark RL. Gynecologic imaging: Expert radiology series. In: Fielding JR, Brown DL, Thurmond AS, eds. Hysterosalpingography. Philadelphia: Saunders, 2011:113-23.

14. Elson EM, Ridley NT. Paracetamol as a prophylactic analgesic for hysterosalpingography: A double blind randomized controlled trial. Clin Radiol 2000;55:675-8.
DISCLOSURES: All authors have no financial relationships to declare with a biotechnology manufacturer, a pharmaceutical company, or other commercial entity that has an interest in the subject matter or materials discussed in the article.

15. Costello MF, Horrowitz S, Steigrad S, Saif N, Bennett M, Ekangaki A. Transcervical intrauterine topical local anesthetic at hysterosalpingography: A prospective, randomized, double-blind, placebo-controlled trial. Fertil Steril 2002;78:1116-22.

16. Guney M, Oral B, Bayhan G, Mungan T. Intrauterine lidocaine infusion for pain relief during saline solution infusion sonohysterography: A randomized, controlled trial. J Minim Invasive Gynecol 2007;14:304-10.

17. Liberty G, Gal M, Halevy-Shalem T, et al. Lidocaine-prilocaine (EMLA) cream as analgesia for hysterosalpingography: A prospective, randomized, controlled, double blinded study. Hum Reprod 2007;22:1335-9.

18. Liberty G, Gal M, Mazaki E, Eldar-Geva T, Vatashsky E, Margalioth EJ. Pain relief of hysterosalpingography by prior uterine cervical application of lidocaine/prilocaine cream. Fertil Steril 2005;84(Suppl 1):127-8

19. Frishman GN, Spencer PK, Weitzen S, Plosker S, Shafi F. The use of intrauterine lidocaine to minimize pain during hysterosalpingography: A randomized trial. Obstet Gynecol 2004;103:1261-6.

20. Bachman EA, Senapati S, Sammel MD, Kalra SK. Randomized controlled trial of benzocaine versus placebo spray for pain relief at hysterosalpingogram. Reprod Biomed Online 2014;28:748-52.

21. Lorino CO, Prough SG, Aksel S, Abuzeid M, Alexander SE, Wiebe RH. Pain relief in hysterosalpingography: A comparison of analgesics. J Reprod Med 1990;35:533-6.

22. Chauhan MB, Lakra P, Jyotsna D, Nanda S, Malhotra V. Pain relief during hysterosalpingography: Role of intracervical block. Arch Gynecol Obstet 2013;287:155-9.

23. Gupta N, Ghosh B, Mittal S. Comparison of oral naproxen and intrauterine lignocaine instillation for pain relief during hysterosalpingography. Int J Gynaecol Obstet 2008;102:284-6.

24. Duffy JM, Ahmad G, Watson AJ. Pain relief during hysterosalpingography: A national survey. Human Fertility 200811:119-21.

25. Ahmad G, Duffy J, Watson AJ. Pain relief in hysterosalpingography. Cochrane Database Syst Rev 2007;(2):CD006106.

26. Tangsiriwatthana T, Sangkomkamhang US, Lumbiganon P, Laopaiboon M. Paracervical local anaesthesia for cervical dilatation and uterine intervention. Cochrane Database Syst Rev 2013;(9):CD005056.

27. Trolice MP, Fishburne C Jr, McGrady S. Anesthetic efficacy of intrauterine lidocaine for endometrial biopsy: A randomized double-masked trial. Obstet Gynecol 2000;95:345-7.

28. Kosus N, Kosus A, Demircioglu RI, et al. Transcervical intrauterine levobupivacaine or lidocaine infusion for pain control during endometrial biopsy. Pain Res Manag 2014;19:82-6.

29. McQuay HJ, Moore A. Methods of Therapeutic Trials. In: McMahon SB, Koltzenburg M, Tracey I, Turk DC, eds. Wall \& Melzack's Textbook of Pain. Philadelphia: Saunders, 2013:402-12. 


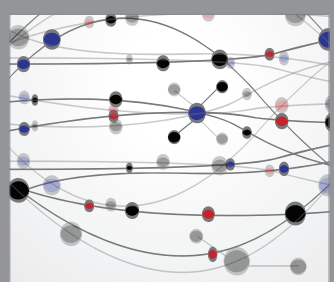

The Scientific World Journal
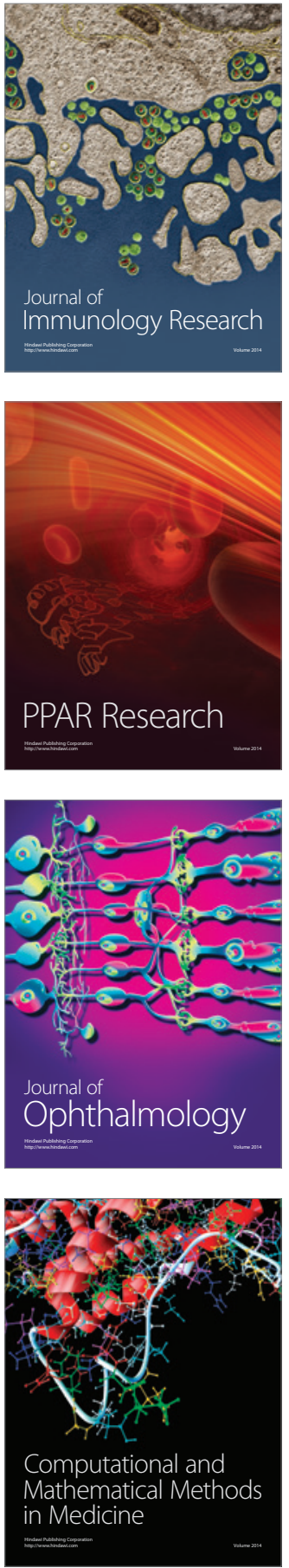

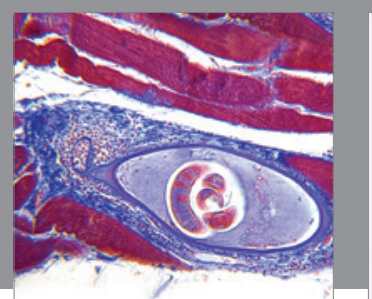

Gastroenterology Research and Practice

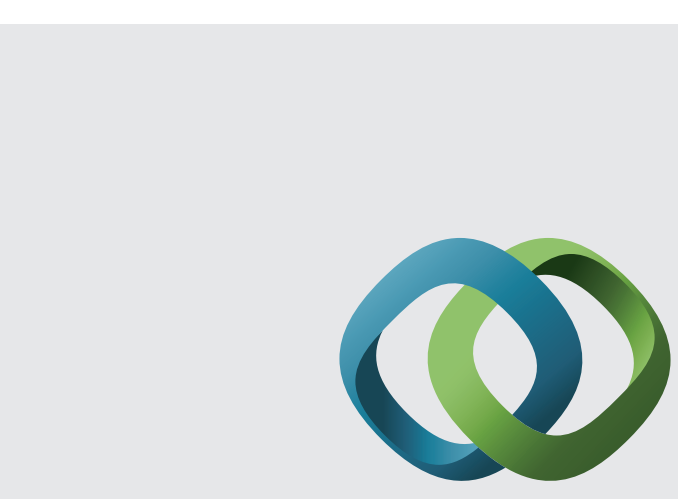

\section{Hindawi}

Submit your manuscripts at

http://www.hindawi.com
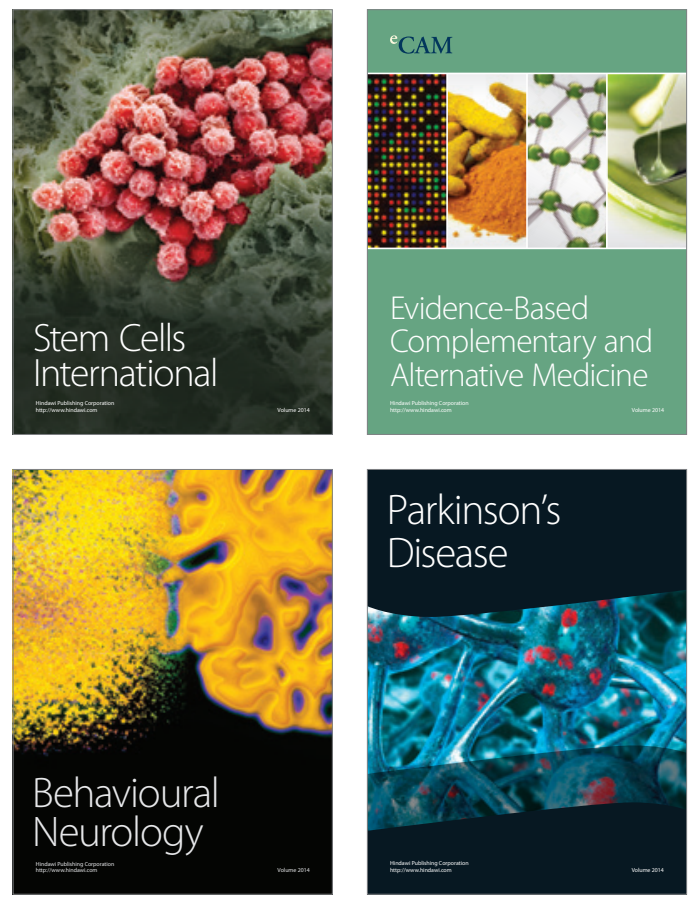
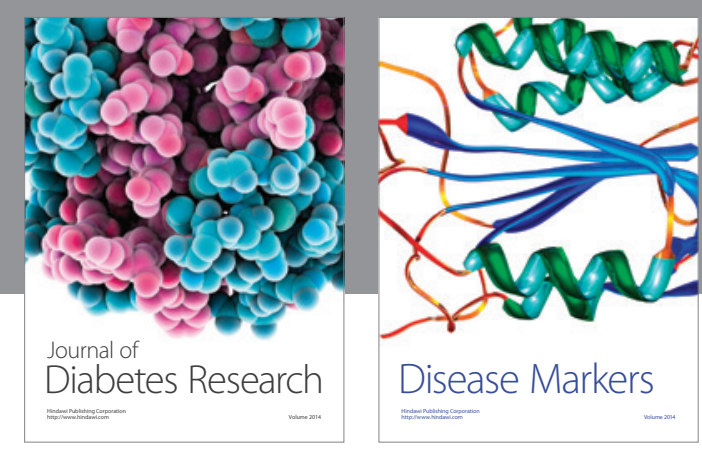

Disease Markers
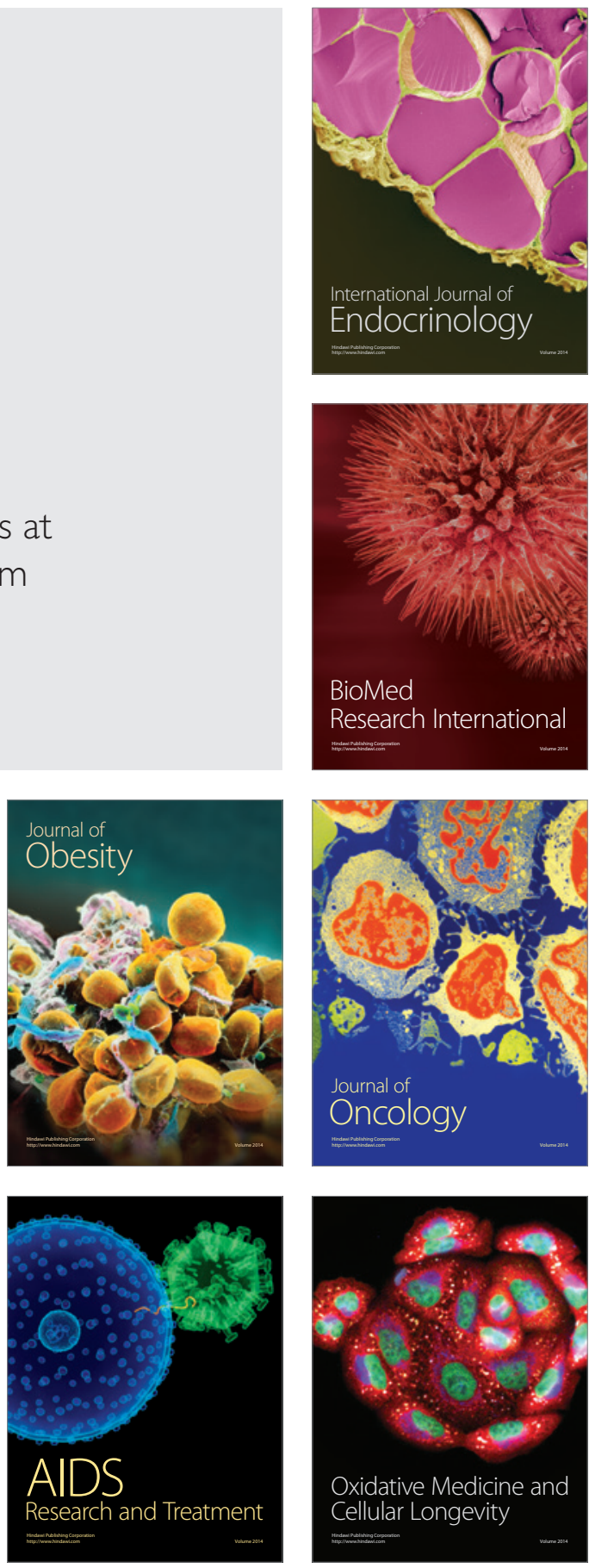